\title{
Nitric Oxide as a Partner of Reactive Oxygen Species Participates in Disease Resistance to Necrotrophic Pathogen Botrytis cinerea in Nicotiana benthamiana
}

\author{
Shuta Asai and Hirofumi Yoshioka \\ Laboratory of Defense in Plant-Pathogen Interactions, Graduate School of Bioagricultural Sciences, Nagoya University, \\ Chikusa, Nagoya 464-8601, Japan
}

Submitted 11 October 2008. Accepted 2 February 2009.

\begin{abstract}
Nitric oxide (NO) is an essential regulatory molecule in plant immunity in synergy with reactive oxygen species (ROS). However, little is known about the role of NO in disease resistance to necrotrophic pathogens. NO and oxidative bursts were induced during necrotrophic fungal pathogen Botrytis cinerea and Nicotiana benthamiana compatible interaction. Histochemical analyses showed that both NO and ROS were produced in adjacent cells of invaded areas in $N$. benthamiana leaves. Activation of salicylic acidinduced protein kinase, which regulates the radical burst, and several defense-related genes were induced after inoculation of $\boldsymbol{B}$. cinerea. Loss-of-function analyses using inhibitors and virus-induced gene silencing were done to investigate the role of the radical burst in pathogenesis. We showed that NO plays a pivotal role in basal defense against $B$. cinerea and PR-1 gene expression in $N$. benthamiana. By contrast, ROS function has a negative role in resistance or has a positive role in expansion of disease lesions during $B$. cinerea-N. benthamiana interaction.
\end{abstract}

Plants have evolved a variety of defense mechanisms to protect themselves against microbial colonization. Plants rely on basal defense by using a much less-specific recognition system that identifies pathogen-associated molecular patterns to prevent penetration and to restrict growth of pathogens (Jones and Dangl 2006). In response to pathogens that avoid, tolerate, or suppress basal defense, plants have evolved resistance $(\mathrm{R})$ proteins that trigger a battery of inducible defense responses as typified by hypersensitive response (HR) upon pathogen recognition, hence gene-for-gene resistance. Cell death during HR is thought to deny nutrients to invading biotrophic pathogens, which can parasitize living plant cells, and to be dependent on balanced production of nitric oxide (NO) and reactive oxygen species (ROS) (Delledonne et al. 2001). NO and ROS are produced simultaneously through a mitogen-activated protein kinase (MAPK)-dependent pathway and play a pivotal role in basal defense (Asai et al. 2008), supported by the view that the MAPK cascade is a central signaling pathway in basal defense as well as in $\mathrm{R}$ protein-dependent resistance (Jones and Dangl 2006).

Corresponding author: Hirofumi Yoshioka; Telephone and Fax: +81-52789-4283; E-mail: hyoshiok@agr.nagoya-u.ac.jp

* The $\boldsymbol{e}$-Xtra logo stands for "electronic extra" and indicates that three supplemental figures are published online.
NO and ROS are important signaling molecules that are rapidly generated after recognition of pathogens, called NO burst and oxidative burst, respectively (Hong et al. 2008; Torres et al. 2006; Wendehenne et al. 2004). In animals, NO is generated by NO synthase (NOS), which converts L-arginine (Arg) to L-citrulline and NO. In plants, two major routes are proposed for NO formation, reduction of nitrite to NO by nitrate reductase and oxidation of Arg to citrulline by NOS. Although evidence for Arg-dependent NO synthesis in plants has accumulated, no gene or protein that has a sequence similar to known mammalian-type NOS has been found in plants (Butt et al. 2003; Garcia-Mata and Lamattina 2003). Guo and associates (2003) identified a NOS-like enzyme from Arabidopsis thaliana (AtNOS1), based on homology to a hypothetical snail NOS. However, AtNOS1 protein has no NOS activity (Zemojtel et al. 2006); therefore, AtNOS1 was renamed AtNOA1 for NO ASSOCIATED1 (Crawford et al. 2006). Recent studies showed that AtNOA1 has circularly permuted GTPase activity (Moreau et al. 2008; Sudhamsu et al. 2008). The function of AtNOA1 remains to be resolved. However, Arabidopsis mutant noal is still useful for its phenotype, which shows reduced levels of NO in plant growth, fertility, hormonal signaling, salt tolerance, and plant-pathogen responses (Guo et al. 2003; He et al. 2004; Zeidler et al. 2004; Zhao et al. 2007). Knocking out or knocking down NOA1 expression provides a powerful tool to analyze NO function.

Plasma membrane NADPH oxidase is a key generator of ROS (Kobayashi et al. 2006). Plant NADPH oxidases designated as respiratory burst oxidase homologs $(\mathrm{RBOH})$ have been identified as genes related to mammalian gp91 ${ }^{\text {phox }}$ (Torres and Dangl 2005; Yoshioka et al. 2001). Genetic evidences for $\mathrm{RBOH}$ function in the pathogen-induced oxidative burst have been provided by knocking out or knocking down $R B O H$. Double mutants of Arabidopsis rbohD and rbohF genes show greatly reduced ROS production in response to infection by avirulent Pseudomonas syringae pv. tomato DC3000 and Hyaloperonospora parasitica (Torres et al. 2002). Analysis of the loss of function of NtRBOHD in tobacco cells (Nicotiana tabacum) shows loss of ROS production by elicitor treatment (Simon-Plas et al. 2002). $\mathrm{NbRBOH}$-silenced $\mathrm{N}$. benthamiana plants show less ROS production in response to infection by the oomycete Phytophthora infestans (Yoshioka et al. 2003). These studies suggest that RBOH is a key regulator of ROS production during defense response.

Most experimental data available on the detection and roles of NO and ROS during plant-pathogen interactions are from 
studies of infections by potential biotrophic pathogens, including bacteria and viruses. NO and oxidative bursts in response to avirulent $P$. syringae were observed in soybean and Arabidopsis suspension-cultured cells (Clarke et al. 2000; Delledonne et al. 1998). Infiltration of mammalian NOS inhibitors into leaves of Arabidopsis ecotype Col-0, which contains the RPM1 resistance gene, leads to reduced accumulation of $\mathrm{NO}$ and increased growth of $P$. syringae pv. maculicola carrying the corresponding avrRpm1 avirulence gene (Delledonne et al. 1998). The Arabidopsis noal knockout mutant shows reduction in NO production and basal defense in response to lipopolysaccharides, and an increase in susceptibility to the virulent bacterial pathogen $P$. syringae pv. tomato DC3000 (Zeidler et al. 2004). Silencing $N b R B O H A$ and $N b R B O H B$ in $N$. benthamiana reduces oxidative burst and disease resistance to $P$. infestans (Yoshioka et al. 2003). These results suggest that the radical burst participates in disease resistance to biotrophic pathogens. However, the roles of radical burst in plant defense responses against necrotrophic pathogens are not fully understood.

The necrotrophic pathogenic fungus Botrytis cinerea, which causes gray mold disease on many dicotyledon plants, secretes a spectrum of phytotoxins and lytic enzymes to kill cells from a wide spectrum of plants (van Kan 2006). Govrin and Levine (2000) proposed that cell death induced by $B$. cinerea is preceded by accumulation of ROS and is an important component of virulence. Increased levels of ROS in plants seem to cause more aggressive infection of $B$. cinerea and result in an accelerated colonization of host tissue (Govrin and Levine 2000; Tiedemann 1997). B. cinerea infection can lead to not only oxidative burst but also depletion of antioxidants in infected and uninfected tissues (Muckenschnabel et al. 2002). Changes in redox balance correspond with a shift toward host cell death and, thus, increased susceptibility to $B$. cinerea. However, ROS production does not always result in increased susceptibility, because failure or success of infection by $B$. cinerea appears to depend on the timing and the intensity of ROS production (Asselbergh et al. 2007; Kunz et al. 2006). B. cinerea endo-polygalacturonase 1 (BcPG1), first known as a virulence factor (ten Have et al. 1998), elicits cell death and several defense responses, including production of NO and ROS and activation of MAPK (Kars et al. 2005; Poinssot et al. 2003; Vandelle et al. 2006). BcPG1-overproducing mutants showing decreased pathogenicity to grape and bean induce a significant and transient ROS production on the leaves (Kunz et al. 2006). Thus, there are several arguments about the role of ROS in defense responses during plants and $B$. cinerea interactions, and little is known about the role of NO as a counterpart of ROS in disease resistance to necrotrophic pathogens.

The MAPK tobacco salicylic acid (SA)-induced protein kinase (SIPK) simultaneously regulates production of $\mathrm{NO}$ and ROS in N. benthamiana (Asai et al. 2008). Activation of MAPK and the radical burst appear to be induced during disease development by Botrytis species (Ren et al. 2008; van Baarlen et al. 2004). In this study, we investigated the role of $\mathrm{NO}$ and oxidative bursts in basal defense against $B$. cinerea in $N$. benthamiana. Histochemical analysis showed that NO and ROS are produced and participate in symptom development of $B$. cinerea in $N$. benthamiana. We also showed that activation of SIPK and several defense-related genes are induced after inoculation of $B$. cinerea. Loss-of-function analyses using in-
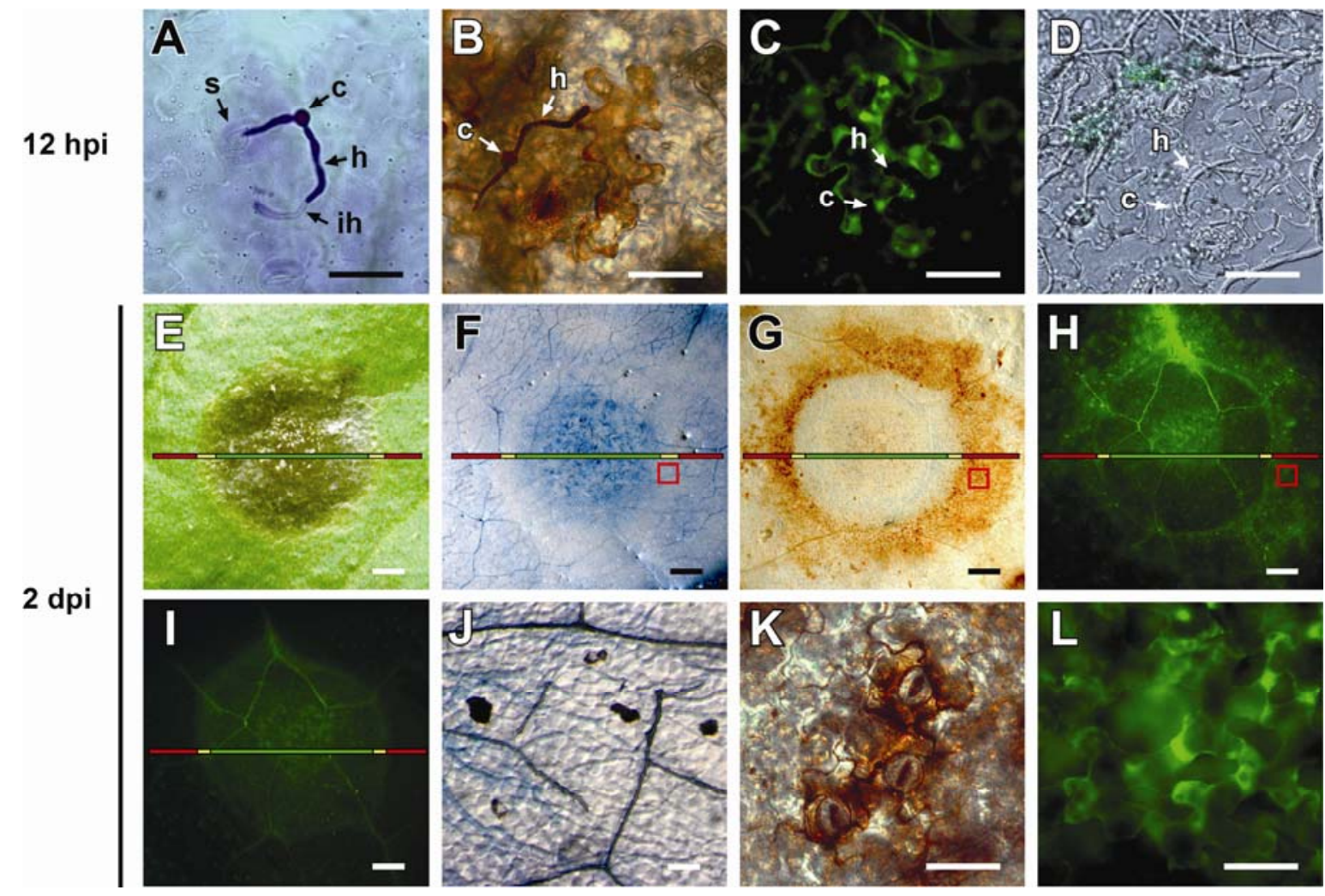

Fig. 1. The radical burst during Botrytis cinerea and Nicotiana benthamiana interaction. N. benthamiana leaves were inoculated with a drop of B. cinerea conidia suspension $\left(5 \times 10^{5}\right.$ conidia/ml), and the results were photographed at $\mathbf{A}$ through $\mathbf{D}, 2$ h postinoculation (hpi) or $\mathbf{E}$ through $\mathbf{L}, 2$ days postinoculation (dpi). Inoculated leaves were stained with trypan blue (A, F, and J) or with 3-3'-diaminobenzidine (B, G, and K) and were treated with 4,5-diaminofluorescein diacetate (DAF-2DA) $(\mathrm{C}, \mathrm{H}$, and $\mathrm{L})$. $\mathrm{C}$ and $\mathrm{D}$ are images at the same position of leaves treated with DAF-2DA, comparing diaminotriazolofluorescein fluorescence $(\mathrm{C})$ with a differential interference contrast image (D). I, Autofluorescence on the DAF2-DA nontreated leaves shown in $\mathrm{H}$. J through L show close-up images of the areas boxed in red in $\mathrm{F}$ through $\mathrm{H}$. A though $\mathrm{D}, \mathrm{c}=$ conidia; $\mathrm{h}=\mathrm{hypha}$; ih $=$ invasion hypha; $\mathrm{s}=\mathrm{stoma}$. E through $\mathrm{I}$, green bars indicate infected areas, yellow bars indicate invaded areas, and red bars indicate response areas. Scale bars $=50 \mu \mathrm{m}(\mathrm{A}$ through $\mathrm{D}$ and $\mathrm{J}$ through $\mathrm{L}), 1 \mathrm{~mm}(\mathrm{E}$ through I). 
hibitors and virus-induced gene silencing (VIGS) showed that NO plays a key role, but ROS have an opposite effect in basal defense against $B$. cinerea.

\section{RESULTS}

Induction of NO and oxidative bursts during $B$. cinerea-N. benthamiana interaction.

We evaluated whether NO and ROS are induced by inoculation with $B$. cinerea in $N$. benthamiana leaves. To observe $B$. cinerea infection, the inoculated leaves were stained by trypan blue, which stains fungal hyphal structures as well as dead cells. At $12 \mathrm{~h}$ postinoculation (hpi), most B. cinerea conidia had germinated and some had penetrated into plant cells (Fig. 1A). Hydrogen peroxide $\left(\mathrm{H}_{2} \mathrm{O}_{2}\right)$ and $\mathrm{NO}$ were detected by 33'-diaminobenzidine (DAB) staining and 4,5-diaminofluorescein diacetate (DAF-2DA)-mediated fluorescence, respectively. As a result, accumulation of $\mathrm{H}_{2} \mathrm{O}_{2}$ and $\mathrm{NO}$ was observed in cells that $B$. cinerea attempted to penetrate (Fig. 1B through D). Disease lesions appeared on leaves at 2 days postinoculation (Fig. 1E). Based on the observation of hyphal elongation of $B$. cinerea, and situation of plant cells, we divided disease lesions into three areas as shown in Figure 1E through I and Supplementary Figure 1. These areas were defined as i) infected areas, the center of lesions, indicating massive hyphae and dead cells resulting from infection; ii) invaded areas, edge of lesions, indicating the apical part of hyphae and progressive cell death; and iii) response areas, regions adjacent to lesion that indicated living cells. In infected areas, accumulation of $\mathrm{H}_{2} \mathrm{O}_{2}$ and $\mathrm{NO}$ was not observed (Fig. $1 \mathrm{~F}$ through $\mathrm{H}$ ). Fluorescence in infected areas and invaded areas without DAF-2DA indicates autofluorescence resulting from fungal infection (Fig. 1I). Hyphae of B. cinerea (Fig. 1J) and little accumulation of $\mathrm{H}_{2} \mathrm{O}_{2}$ and $\mathrm{NO}$ (Fig. $1 \mathrm{G}$ and $\mathrm{H}$ ) were in invaded areas. Marked accumulation of $\mathrm{H}_{2} \mathrm{O}_{2}$ and $\mathrm{NO}$ was found in the response areas (Fig. $1 \mathrm{~K}$ and $\mathrm{L}$ ). These results indicate that $\mathrm{NO}$ and oxidative bursts are induced before $B$. cinerea invasion.

\section{Inhibition of NO and oxidative bursts affects susceptibility to $B$. cinerea.}

To evaluate the effects of the radical burst on susceptibility to $B$. cinerea, we used diphenylene iodonium (DPI), known as an inhibitor of not only NADPH oxidase (Govrin and Levine 2000) but also of NOS (Ma et al. 2008), and $\mathrm{N}^{\mathrm{G}}$ nitro-L-Arg-methyl ester (L-NAME), a NOS inhibitor. $B$. cinerea conidia were inoculated in drops onto leaf areas infiltrated with inhibitors or with $\mathrm{H}_{2} \mathrm{O}$ as a control $1 \mathrm{~h}$ before inoculation. NO burst was detected by DAF-2DA-mediated fluorescence, and the inducible fluorescence was eliminated by 2-4-carboxyphenyl-4,4,5,5-tetramethylimidazoline-1-oxyl3-oxide (cPTIO), a NO scavenger (Fig. 2A and B), indicating that DAF-2DA detects NO. Timecourse experiments showed that the DAF-2DA-mediated fluorescence was slightly detected at 6 hpi and peaked at 12 hpi (Supplementary Fig. 2). We did not observe autofluorescence without DAF-2DA at this stage. Therefore, DAF-2DA-mediated fluorescence intensities were measured at 12 hpi in the following experiments. DPI treatment slightly suppressed NO burst induced by $B$. cinerea inoculation as compared with $\mathrm{H}_{2} \mathrm{O}$ treatment (Fig. $2 \mathrm{~A}$ and $\mathrm{B})$. However, L-NAME-infiltrated leaf areas showed marked reduction of NO burst (Fig. 2A and B). D-NAME, an inactive isomer of L-NAME, had no effect on NO burst (Fig. $2 \mathrm{~A}$ and $\mathrm{B}$ ). These results suggest that NOS-like NO-generating activity might participate in NO burst induced by $B$. cinerea inoculation.

To detect ROS induced by $B$. cinerea, inoculated leaves were infiltrated with L-012 solution, a highly sensitive and specific agent to detect ROS (Asai et al. 2008; Kobayashi et al. 2007), and were observed by using a sensitive CCD camera. Timecourse experiments showed that L-012-mediated chemiluminescence was detected at $12 \mathrm{hpi}$ but not at $6 \mathrm{hpi}$; thereafter, much production of ROS was observed at 24 hpi (Supplemen-
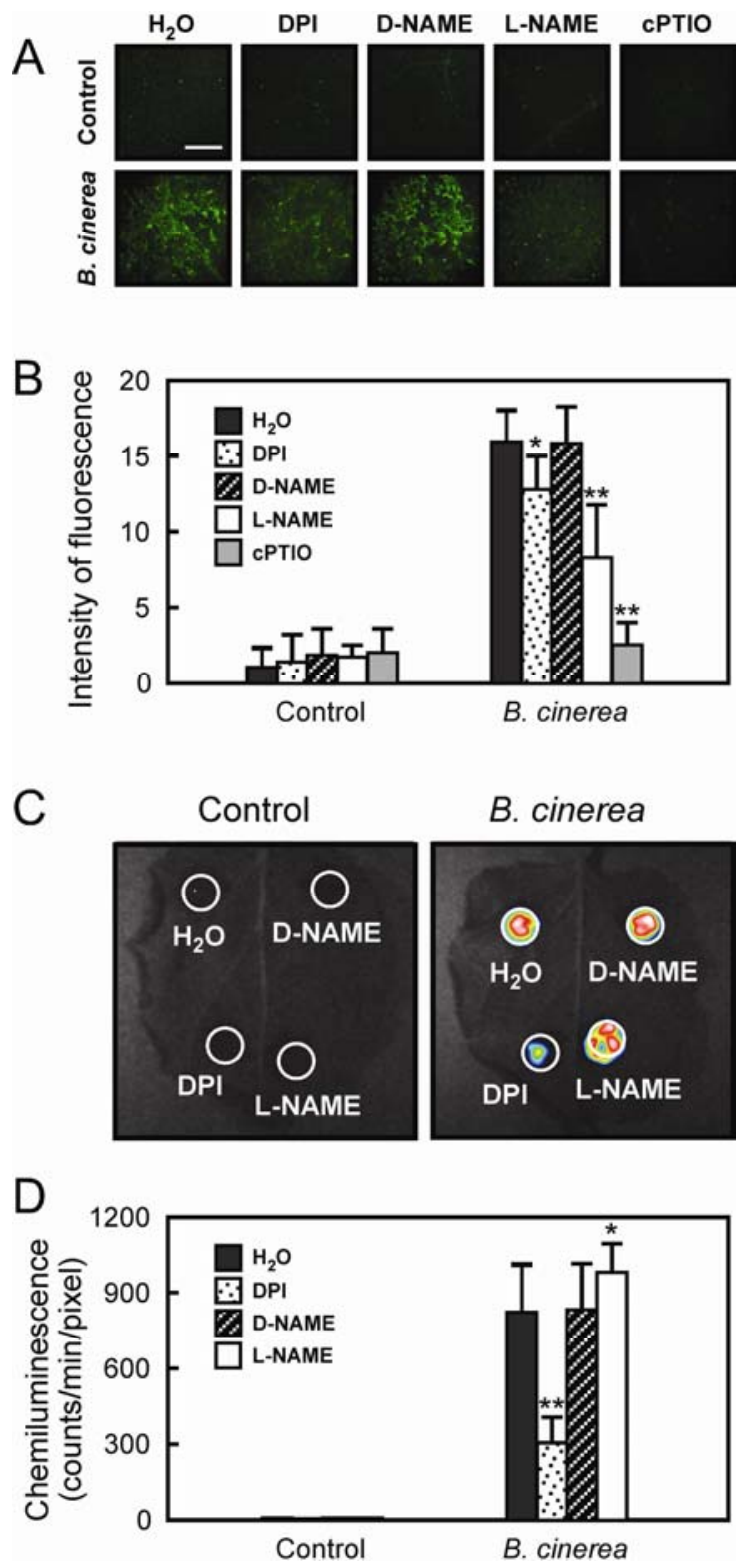

Fig. 2. Effects of inhibitors on the radical burst during Botrytis cinerea and Nicotiana benthamiana interaction. N. benthamiana leaves were infiltrated with diphenylene iodonium (DPI) $(50 \mu \mathrm{M})$, D-NAME $(5 \mathrm{mM})$, LNAME $(5 \mathrm{mM})$, or $\mathrm{H}_{2} \mathrm{O}$ as a control $1 \mathrm{~h}$ before inoculation and were then inoculated with B. cinerea or potato dextrose broth (Control). A, At $12 \mathrm{~h}$ postinoculation (hpi), the inoculated leaf areas were infiltrated with 4,5diaminofluorescein diacetate (DAF-2DA) solution and were then monitored $1 \mathrm{~h}$ later using fluorescence stereomicroscopy. In the case of 2-4-carboxyphenyl-4,4,5,5-tetramethylimidazoline-1-oxyl-3-oxide (cPTIO), inoculated-leaf areas were infiltrated with cPTIO $(500 \mu \mathrm{M}) 1 \mathrm{~h}$ before infiltration of DAF-2DA. Scale bars $=1 \mathrm{~mm}$. B, Signal intensities were quantified by determining the mean green-channel values for the images with the histogram function. Data are means \pm standard deviation (SD) from three experiments. Data were subjected to Student's $t$-test. $* P<0.19$ and $* * P<$ 0.05 versus the $\mathrm{H}_{2} \mathrm{O}$ control treatment. C, Inoculated leaf areas were infiltrated with L-012 solution (a reagent to detect reactive oxygen species) 12 hpi and were monitored using a CCD camera. White circles indicate areas infiltrated with L-012. D, Chemiluminescence intensities were quantified. Data are means \pm SD from five experiments. Data were subjected to Student's $t$-test. $* P<0.17$ and $* * P<0.05$ versus the $\mathrm{H}_{2} \mathrm{O}$ control treatment. 
tary Fig. 3). However, ROS production was determined at 12 hpi in the following experiments because some leaf tissues showed a cell-death phenotype at 24 hpi. B. cinerea-inducible oxidative burst markedly decreased with DPI treatment compared with the oxidative burst in leaf areas infiltrated with $\mathrm{H}_{2} \mathrm{O}$ (Fig. 2C and D), suggesting that the oxidative burst induced by $B$. cinerea depends on NADPH oxidase. By contrast, leaf areas infiltrated with L-NAME showed slight increases in accumulation of ROS and D-NAME had no effect on the oxidative burst (Fig. 2C and D). These results suggest that $B$. cinerea-inducible oxidative burst is regulated negatively by NO.

We evaluated the effects of inhibitors on susceptibility to $B$. cinerea. Susceptibility to $B$. cinerea was assessed by measuring diameter of disease lesions and ion leakage as an index of cell death (Fig. 3). DPI-treated leaf areas showed slight reduction in disease symptoms compared with $\mathrm{H}_{2} \mathrm{O}$-treated leaf areas (Fig. 3). By contrast, leaf areas infiltrated with L-NAME, although not D-NAME, showed marked expanding disease lesions compared with leaf areas infiltrated with $\mathrm{H}_{2} \mathrm{O}$ (Fig. 3). These results suggest that the oxidative burst induced by $B$. cinerea has a positive impact on expansion of disease lesions and that NO participates in resistance to $B$. cinerea. We also assessed the dose effects of inhibitors on growth of $B$. cinerea to rule out the possibility that the difference in disease lesions is due to inhibitory effects on growth of B. cinerea by inhibi-

\section{A}
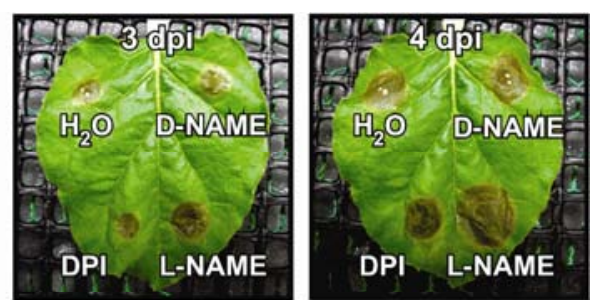

B
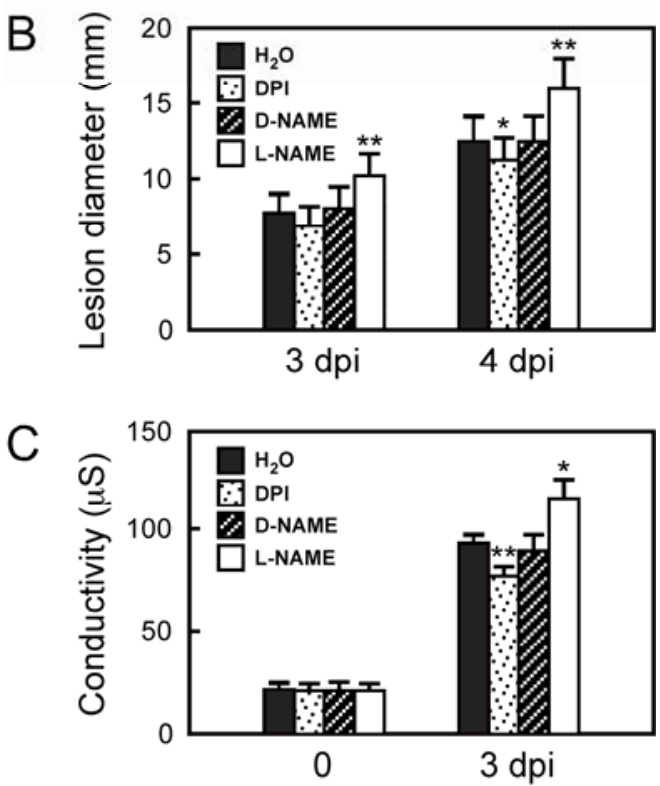

Fig. 3. Effects of inhibitors on susceptibility to Botrytis cinerea. Nicotiana benthamiana leaves infiltrated with inhibitors or $\mathrm{H}_{2} \mathrm{O}$ were inoculated with $B$. cinerea. A, Necrotic lesions in B. cinerea-inoculated leaves at 3 and 4 days postinoculation (dpi). B, Average diameter of lesions formed on the leaves at 3 and $4 \mathrm{dpi}$. Data are means \pm standard deviation (SD) from 10 experiments. Data were subjected to Student's $t$-test. $* P<0.18$ and $* * P<0.01$ versus the $\mathrm{H}_{2} \mathrm{O}$ control treatment. C, Quantification of cell death at 0 and 3 dpi. Data are means \pm SD from three experiments. Data were subjected to Student's $t$-test. ${ }^{*} P<0.05$ and ${ }^{*} * P<0.01$ versus the $\mathrm{H}_{2} \mathrm{O}$ control treatment. tors. Although cycloheximide, an inhibitor of de novo protein synthesis, pronouncedly inhibited growth of $B$. cinerea, DPI, L-NAME, and D-NAME treatments at the concentrations that were used in susceptibility analysis in Figure 3 had no effect on growth of $B$. cinerea on potato dextrose agar (PDA) (Fig. 4).

SIPK and defense-related genes activated during $B$. cinerea- $N$. benthamiana interaction.

The MAPK cascade MEK2-SIPK regulates NbNOA1-mediated NO burst and oxidative burst accompanied by expression of $N b R B O H B$, which is an inducible form of NADPH oxidase of $N$. benthamiana (Asai et al. 2008). NO and oxidative bursts were induced during $B$. cinerea- $N$. benthamiana interaction (Figs. 1 and 2). Therefore, we evaluated if enzyme activity of SIPK and transcription of $N b R B O H B$ are activated by $B$. cinerea inoculation. $N$. benthamiana leaves were inoculated with B. cinerea conidia. Activation of SIPK (Fig. 5A) and the expression of $\mathrm{NbRBOHB}$ (Fig. 5B) were markedly induced at 12 hpi, in agreement with the timing of NO and ROS induced after inoculation with $B$. cinerea. $N b N O A l$ expression was decreased by inoculation with $B$. cinerea (Fig. 5B), as reported by Kato and associates (2008). These results indicate that activation of SIPK might participate in NO and oxidative bursts after recognition of $B$. cinerea in $N$. benthamiana.

Genetic approaches have showed that SA, jasmonic acid (JA), and ethylene (ET) signaling also participate in disease resistance to B. cinerea in Arabidopsis thaliana (Ferrari et al. 2003; van Baarlen et al. 2007). To evaluate if SA, JA, and ET signaling are induced after inoculation with $B$. cinerea in $N$. benthamiana, we assessed the expression of the SA-responsive gene $N b P R-1$, JA synthesis-related gene $N b L O X$, and ETresponsive gene $N b E R F 1$ after inoculation. Semiquantitative reverse transcriptase-mediated polymerase chain reaction (RT$\mathrm{PCR}$ ) showed marked induction of the expression of $N b P R-1$, $N b L O X$, and $N b E R F 1$ (Fig. 5B), suggesting induction of SA, $\mathrm{JA}$, and ET signaling during $B$. cinerea-N. benthamiana interaction. We also evaluated if the expression of radical-responsive genes $\mathrm{NbGST}$ and $\mathrm{NbCAT1}$ (Zago et al. 2006; Vandenabeele et al. 2003) are induced after inoculation with $B$. cinerea. At 12 hpi, both $N b G S T$ and $N b C A T 1$ were induced (Fig. 5B). The timing of $N b G S T$ and $N b C A T 1$ expression was well matched with the production of $\mathrm{NO}$ and ROS.

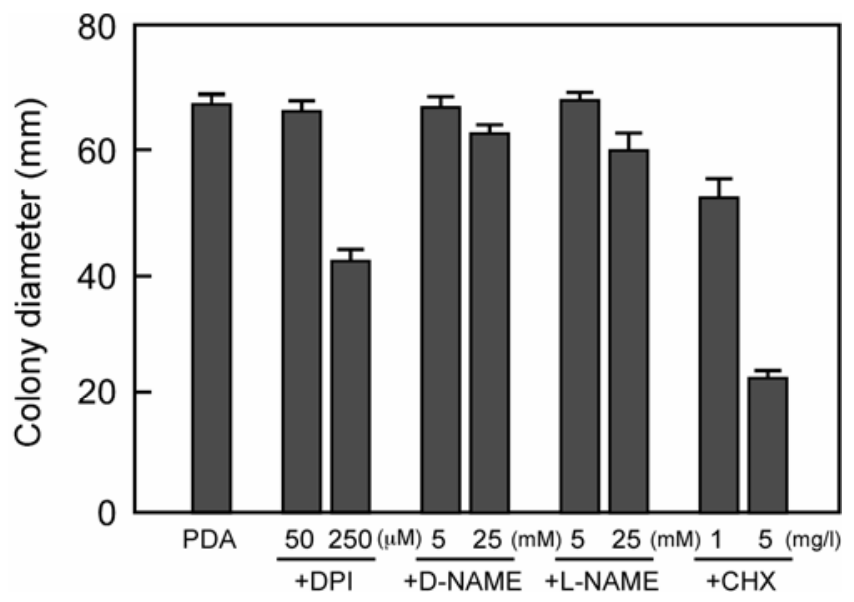

Fig. 4. Effects of inhibitors on growth of Botrytis cinerea on potato dextrose agar (PDA) plates. PDA plates including diphenylene iodonium (DPI) $(50 \mu \mathrm{M}$ or $250 \mu \mathrm{M})$, D-NAME $(5 \mathrm{mM}$ or $25 \mathrm{mM})$, L-NAME ( $5 \mathrm{mM}$ or $25 \mathrm{mM})$, or cycloheximide $(\mathrm{CHX})(1 \mathrm{mg} /$ liter or $5 \mathrm{mg} /$ liter $)$ and intact PDA plates as a control were inoculated with $B$. cinerea. Colony diameters were measured at 3 days postinoculation. Data are means \pm standard deviation from four experiments. 
Silencing $N b N O A 1$ and $N b R B O H B$ affects susceptibility to $B$. cinerea.

NOA1 participates in NO generation induced by abscisic acid, salt stress, and elicitors (Asai et al. 2008; Guo et al. 2003; Zhao et al. 2007). ROS generation induced by elicitors and after recognition of pathogens depends on NbRBOHB in N. benthamiana (Asai et al. 2008; Yoshioka et al. 2003). Pharmacological analyses in this study showed that NOS-like NO-generating activity and NADPH oxidase take part in $B$. cinerea-inducible NO and oxidative bursts, respectively, in $N$. benthamiana leaves (Fig. 2). To clarify the relationship between the radical burst and disease resistance to $B$. cinerea, we silenced either $N b N O A 1, N b R B O H B$, or both in $N$. benthamiana by VIGS. Tobacco rattle virus (TRV) vector containing cDNA fragments of $N b N O A l$ and $N b R B O H B$ was introduced into $N$. benthamiana by Agrobacterium infiltration (Ratcliff et al. 2001). Three weeks after infiltration, the effectiveness of the silencing was monitored by using RTPCR. NbNOAl and $N b R B O H B$ transcripts markedly decreased in the silenced plants as compared with the control plants infected with TRV vector alone (Fig. 6A). NbNOAl- and $\mathrm{NbNOAI}$ and $\mathrm{NbRBOHB}$-silenced plants but not $\mathrm{NbRBOHB}$ silenced plants showed significant reduction in NO burst induced by inoculation with $B$. cinerea compared with TRV control plants (Fig. 6B). However, oxidative burst induced by $B$. cinerea inoculation was eliminated in $\mathrm{NbRBOHB}$ - and NbNOAl and NbRBOHB-silenced plants (Fig. 6C). NbNOAl

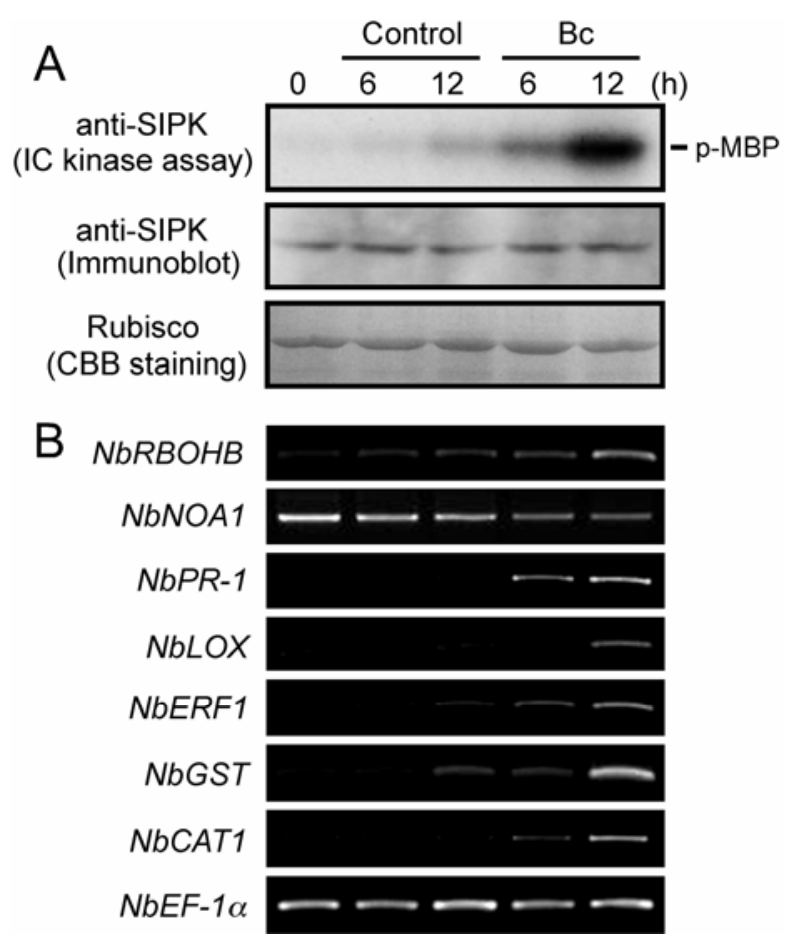

Fig. 5. Activation of salicylic acid-induced protein kinase (SIPK) and defense-related genes by inoculation with Botrytis cinerea. Total protein and RNA were extracted from intact leaves $(0)$ or from leaves inoculated with B. cinerea or potato dextrose broth (Control) at the indicated times (h). A, Kinase activities of the extracts were assayed by immunocomplex (IC) kinase assay with SIPK-specific antiserum using myelin basic protein (MBP) as a substrate. Immunoblot analyses were done using SIPK-specific antiserum. Protein loads were monitored by Coomassie blue (CBB) staining bands corresponding to the ribulose-1,5-bisphosphate carboxylase (Rubisco) large subunit. B, Total RNA was used for reverse transcriptasemediated polymerase chain reaction with specific primers for $\mathrm{NbRBOHB}$, NbNOA1, NbPR-1, NbLOX, NbERF1, NbGST, and NbCAT1. Equal loads of cDNA were monitored by amplification of constitutively expressed $N b E F-1 \alpha$. silencing markedly induced oxidative burst compared with TRV control plants (Fig. 6C). These results suggest that $B$. cinerea causes NbNOA1-mediated NO burst and NbRBOHBdependent oxidative burst in $N$. benthamiana.

Conidia of $B$. cinerea were inoculated in drops onto the surface of silenced leaves of $N$. benthamiana. NbNOAl-and $N b N O A 1$ and $N b R B O H B$-silenced plants showed yellowish leaves (Fig. 7A), which were similar to leaves of the Arabidopsis noal knockout mutant (Flores-Perez et al. 2008; Guo et al. 2003). The phenotype is distinct from disease symptoms by $B$. cinerea infection. $N b N O A l$-silenced leaves showed high susceptibility to $B$. cinerea, but $N b R B O H B$-silenced leaves showed marked reduction in the size of disease lesions compared with TRV control leaves (Fig. 7). Because marked increases in ROS generation were in NbNOAl-silenced leaves, these results suggest that ROS generated from plants participate in expansion of disease lesions by $B$. cinerea or negatively function in disease resistance to $B$. cinerea. $N b N O A 1$ and $N b R B O H B$-silenced leaves showed expansion
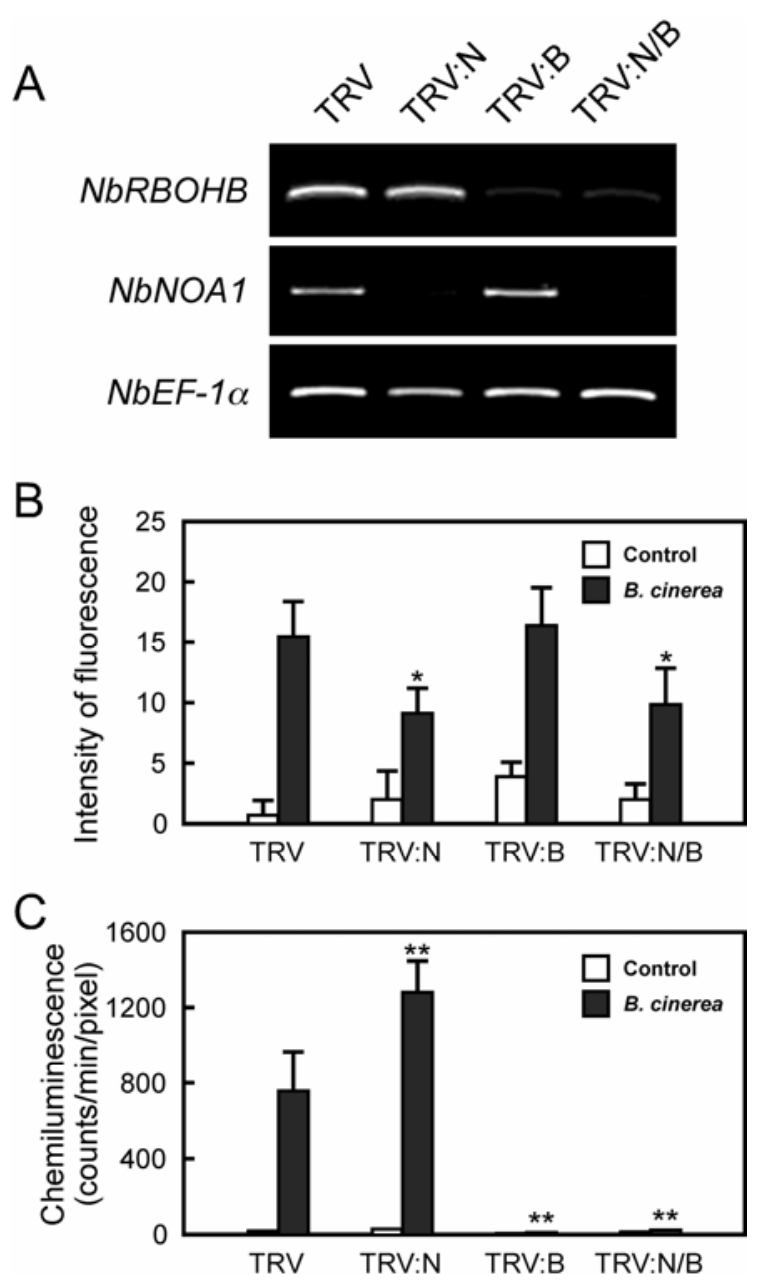

Fig. 6. Silencing $N b N O A 1$ and $N b R B O H B$ compromises the radical burst induced by Botrytis cinerea. At 3 weeks after inoculation with Tobacco rattle virus (TRV) gene-silencing constructs TRV:NbNOA1 (N), TRV: NbRBOHB (B), TRV:NbNOA1/NbRBOHB (N/B), and TRV as a control, silenced leaves were inoculated with $B$. cinerea or potato dextrose broth (Control). A, Total RNA extracted from silenced leaves at $12 \mathrm{~h}$ postinoculation (hpi) was used for reverse transcriptase-mediated polymerase chain reaction with specific primers for $N b R B O H B$ and $N b N O A 1$. Equal loads of cDNA were monitored by amplification of constitutively expressed $N b E F-1 \alpha$. B, Measurements of nitric oxide and $\mathbf{C}$, reactive oxygen species were done at $12 \mathrm{hpi}$. Data are means \pm standard deviation from four experiments. Data were subjected to Student's $t$-test. ${ }^{*} P<0.05$ and $* * P<0.01$ versus the TRV control. 


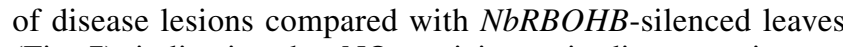
(Fig. 7), indicating that NO participates in disease resistance to $B$. cinerea.

\section{SIPK activation and defense-related gene expression in $\mathrm{NbNOA1}$ - and $\mathrm{NbRBOHB}$-silenced plants.}

Activation of SIPK and the expression of defense-related genes are induced by inoculation with $B$. cinerea in $N$. benthamiana (Fig. 5). We evaluated the effects of silencing NbNOA1, $N b R B O H B$, or both on SIPK activation and defense-related gene expression. Using RT-PCR, we confirmed reduced accumulation of $N b N O A l$ and $N b R B O H B$ transcripts in silenced plants either mock-inoculated or inoculated with $B$. cinerea compared with corresponding control plants infected with TRV alone (Fig. 8). NbNOAl- and NbNOAl and NbRBOHBsilenced plants showed marked reduction of ribulose-1,5bisphosphate carboxylase (Rubisco) large subunit protein levels (Fig. 8A), consistent with the decrease in mutants of Arabidopsis noal (also called rifl for resistant to inhibition by FSM) (Flores-Perez et al. 2008). Knockout of Atnoal influences ribosome activity resulting in defects in protein translation, eventually leading to decreased levels of plastome-encoded proteins (i.e., depletion of Rubisco levels) (Flores-Perez et al. 2008). We confirmed not only activation of SIPK but also its protein levels by immunoblot analysis in silenced plants. Silencing $N b N O A 1, N b R B O H B$, or both had no effect on protein levels and activation of SIPK induced at $12 \mathrm{~h}$ after inoculation with $B$. cinerea conidia as compared with TRV control plants (Fig. 8A). Expression of $N b P R-1$ but not $N b L O X$ and NbERFl decreased in NbNOAl- and NbNOAl and NbRBOHBsilenced plants (Fig. 8B), suggesting the influence of NOA1mediated NO in SA signaling. We also evaluated the expression of radical-responsive genes in silenced plants. Expression of $N b G S T$ and $N b C A T 1$ was compromised in $N b N O A 1$ and NbRBOHB-silenced plants but not in NbNOAl- and $\mathrm{NbRBOHB}$-silenced plants (Fig. 8B). The results correspond to studies in which GST and CAT1 were induced by both NO and ROS (Xing et al. 2008; Zago et al. 2006).

\section{DISCUSSION}

This study showed that NO contributes to disease resistance against $B$. cinerea in $N$. benthamiana. By contrast, ROS function negatively in resistance or positively in expansion of disease lesions during $B$. cinerea-N. benthamiana interaction.

Plants are subject to attack by a wide variety of microbial pathogens. From the viewpoint of pathogen biology, the death of host cells, which is common as an effective plant defense mechanism during gene-for-gene resistance (i.e., HR), may be advantageous for necrotrophic pathogens feeding on dead matter, but it is disadvantageous for biotrophic pathogens feeding on living host tissue. Although the mechanisms of the genetic composition of the host and gene-for-gene dependencies in relation to necrotrophic pathogens remain to be clarified, many studies have investigated the relationship between HR cell death and necrotrophic pathogens. Studies of $A$. thaliana and tobacco suggested that $B$. cinerea may even need HR cell death to achieve full pathogenicity (Dickman et al. 2001; Govrin and Levine 2000). A. thaliana mutants with delayed or reduced cell-death response are generally more resistant to $B$. cinerea infection, but mutants in which cell death is accelerated are more susceptible (van Baarlen et al. 2007). HR cell death requires coordinated levels of NO and ROS (Delledonne et al. 2001). MAPK cascade MEK2-SIPK regulates NO burst and oxidative burst accompanied by induction of $\mathrm{NbRBOHB}$ expression in $N$. benthamiana (Asai et al. 2008). In this study, accumulation of NO and ROS in the same region was observed after infection by $B$. cinerea on $N$. benthamiana leaves (Fig. 1 ), in agreement with production of NO and ROS in compatible lily-B. elliptica interaction (van Baarlen et al. 2004). The radical burst was induced at $12 \mathrm{hpi}$, in agreement with the activation profile of SIPK (Fig. 5A) and with the expression pro-
A

TRV



B

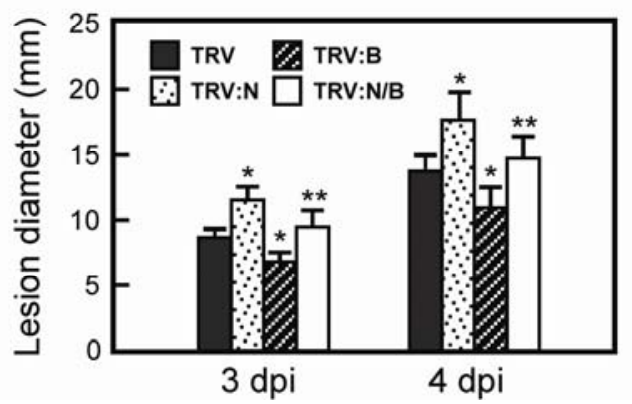

TRV:B
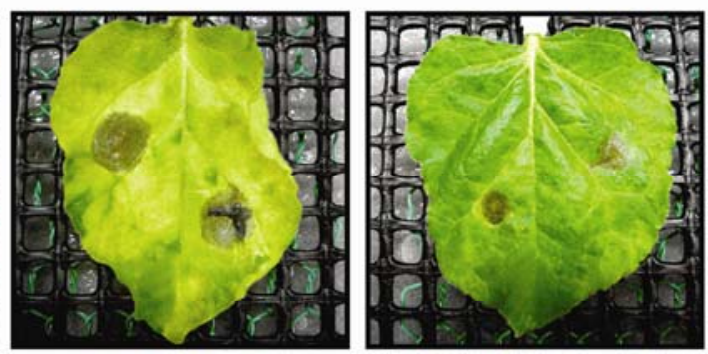

C

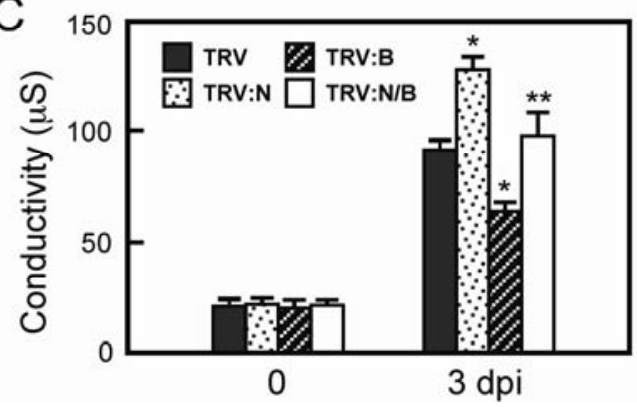

Fig. 7. Effects of silencing $N b N O A 1(\mathrm{~N}), N b R B O H B(\mathrm{~B})$, or $N b N O A 1 / N b R B O H B(\mathrm{~N} / \mathrm{B})$ on susceptibility to Botrytis cinerea. Silenced leaves were inoculated with $B$. cinerea. A, Inoculated leaves were photographed at 3 days postinoculation (dpi). B, Average diameter of lesions formed on the leaves at 3 and 4 dpi. Data are means \pm standard deviation (SD) from 10 experiments. C, Quantification of cell death at 0 and 3 dpi. Data are means \pm SD from three experiments. Data were subjected to Student's $t$-test. $* P<0.01$ versus the Tobacco rattle virus (TRV) control. $* * P<0.01$ versus the $N b R B O H B$ silenced plants. 
file of $\mathrm{NbRBOHB}$ (Fig. 5B). BcPG1 is a virulence factor of $B$. cinerea (ten Have et al. 1998) and induces the radical burst, MAPK activation, and cell death (Kars et al. 2005; Poinssot et al. 2003; Vandelle et al. 2006). B. cinerea may elicit defense responses of host plants (i.e., MAPK activation, NO and ROS production) to induce HR cell death for its own advantage. Paradoxically, a nonpathogenic mutant overproducing BcPG1 induces an HR-like reaction on grape and bean leaves in relation to a cessation of tissue colonization (Kunz et al. 2006), suggesting that HR cell death has an important role in B. cinerea virulence but may also be responsible for resistance, depending on the timing and strength of HR. In this study, we confirmed little accumulation of NO and ROS in invaded areas (Fig. 1, yellow bar) in which the hyphae of $B$. cinerea were observed. Depletion of the radical burst in invaded areas may be caused by $B$. cinerea. An oxidative burst-suppressing agent is included in the $B$. cinerea isolate B 1.12 suspension classified as aggressive but not in the isolate B 1.7 suspension classified as nonaggressive (Unger et al. 2005). In the abscisic acid-deficient tomato mutant, which is highly resistant to $B$. cinerea, accumulation of $\mathrm{H}_{2} \mathrm{O}_{2}$ was earlier and stronger than in the susceptible wild type at the site of infection (Asselbergh et al. 2007). Furthermore, accumulation of NO and ROS in response to $B$. cinerea was delayed in susceptible but not in resistant pelargonium (Floryszak-Wieczorek et al. 2007), suggesting development of disease or elimination of the pathogen is determined by speed and efficiency of the radical burst initiated by plants.

Genetic and pharmacological approaches showed that reduced endogenous NO levels lead to increased levels of ROS and oxidized lipids and proteins under ultraviolet and salt stresses (Shi et al. 2005; Zhao et al. 2007). Consistent with these studies, we showed that treatment with a mammalian NOS inhibitor and NbNOAl silencing compromise NO production and ROS accumulation increases after inoculation with $B$. cinerea (Figs. 2 and 6). NO can react very quickly with superoxide $\left(\mathrm{O}_{2}^{-}\right)$to form peroxynitrite $\left(\mathrm{ONOO}^{-}\right)$and thus decrease the amount of endogenous ROS. Interestingly, the radical burst was observed in tissues adjacent to disease lesions (i.e., response areas, red bar in Fig. 1). B. cinerea infection can lead to accumulation of free radicals in uninfected tissue (Muckenschnabel et al. 2001, 2003) and depletion of antioxidants (Muckenschnabel et al. 2002). These events that increase oxidative processes may be caused by $B$. cinerea to facilitate infection. Treatment of crop plants with various antioxidants and then by inoculation with $B$. cinerea results in markedly inhibited development of gray mold disease (Elad 1992). NO appears to act as an antioxidant of ROS in disease resistance to $B$. cinerea. Our results also showed that NO production during $B$. cinerea interaction was partially reduced by a mammalian NOS inhibitor and NbNOAl silencing, indicating that the sources of NO synthesis except NOS, such as nitrate reductase, might participate in NO production in response to $B$. cinerea. Plants may produce NO by more than one NO-producing system after recognition of $B$. cinerea to hold out against $B$. cinerea.

NO signaling includes complex processes that include increases in cytosolic $\mathrm{Ca}^{2+}$ concentration, cyclic GMP, cyclic ADP ribose, and protein kinases. $\mathrm{NO}$ also modulates protein activities directly by cysteine $S$-nitrosylation (Besson-Bard et al. 2008). The relationship between $\mathrm{NO}$ and SA, an important regulator of plant defense responses, has been studied (Klessig et al. 2000). $S$-nitrosylation of NPR1, a master regulator of SA, regulates its reaction between oligomer and monomer and maintains its homeostasis upon SA induction (Tada et al. 2008). SA signalingdeficient mutants of $A$. thaliana show high susceptibility to $B$. cinerea (Ferrari et al. 2003; van Baarlen et al. 2007), suggesting that SA signaling takes part in disease resistance to $B$. cinerea. In this study, silencing of $N b N O A l$ and both $N b N O A l$ and $N b R B O H B$ reduced the expression of the SA-responsive gene $N b P R-1$ induced by inoculation with $B$. cinerea (Fig. 8). These results suggest that reduced basal defense against $B$. cinerea in $N$. benthamiana resulting from compromised endogenous NO production may be due to depletion of SA signaling.

The mechanism and site for NO and ROS syntheses in pathogenic microorganisms challenging the plants have been studied. NO accumulates in germinating conidia at all stages of Colletotrichum coccodes and is required for the regulation of germination and elongation depending on the developmental stages (Wang and Higgins 2005). NO has a role in appressorial maturation of Blumeria graminis (Prats et al. 2008). B. cinerea also appears to produce NO as reported by FloryszakWieczorek and associates (2007). On the other hand, knockout mutants of $B$. cinerea NADPH oxidase genes have great impact on penetration and colonization (Segmuller et al. 2008), indicating that NADPH oxidases are indispensable for pathogenicity of $B$. cinerea. Although inhibitor treatments had no effect on the growth of $B$. cinerea on a PDA plate (Fig. 4), they may affect the differentiation and pathogenicity of $B$. cinerea in plants. In this study, we did knockdown analyses by VIGS to find the contribution of NO produced from plants in

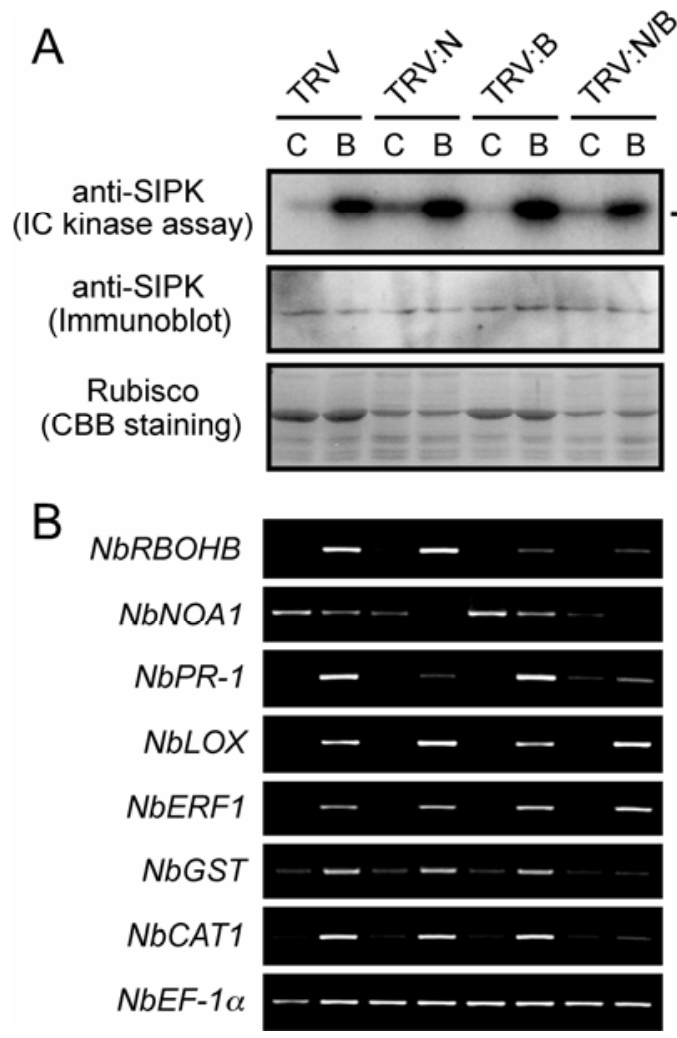

Fig. 8. Effects of silencing $N b N O A 1(\mathrm{~N}), N b R B O H B(\mathrm{~B})$, or $N b N O A 1 /$ $\mathrm{NbRBOHB}(\mathrm{N} / \mathrm{B})$ on activation of salicylic acid-induced protein kinase (SIPK) and defense-related genes by inoculation with Botrytis cinerea. Total protein and RNA were extracted from silenced leaves inoculated with $B$. cinerea (B) and potato dextrose broth (C) as a control at $12 \mathrm{~h}$ postinoculation. A, Kinase activities of the extracts were assayed by immunocomplex (IC) kinase assay with SIPK-specific antiserum using myelin basic protein (MBP) as a substrate. Immunoblot analyses were done using SIPK-specific antiserum. Protein loads were monitored by Coomassie blue (CBB) staining bands corresponding to the ribulose-1,5-bisphosphate carboxylase (Rubisco) large subunit. B, Reverse transcriptase-mediated polymerase chain reaction with specific primers for $N b R B O H B, N b N O A 1$, $N b P R-1, N b L O X, N b E R F 1, N b G S T$, and $N b C A T 1$ was performed. Equal loads of cDNA were monitored by amplification of constitutively expressed $N b E F-1 \alpha$. 
disease resistance against $B$. cinerea (Fig. 7). The function of $\mathrm{NO}$ and ROS derived from $B$. cinerea remains to be clarified. Further studies are needed to clarify the role of radicals in the cross-talk between plants and necrotrophic pathogens.

Recent studies indicated that the effects of the radical burst on defense response appear to be diverse in plant-pathogen interactions. In $N$. benthamiana, $N b R B O H B$ silencing has a strong effect on resistance to the potential biotrophic pathogen $P$. infestans but not to the hemibiotrophic pathogen $C$. orbiculare (syn. C. lagenarium), whereas NbNOAl silencing induces high susceptibility to $C$. orbiculare but not to $P$. infestans (Asai et al. 2008). Our preliminary data indicate that transgenic potato (Solanum tuberosum) plants expressing a constitutively active form of the calcium-dependent protein kinase StCDPK5 (StCDPK5VK), which activates StRBOH (Kobayashi et al. 2007), fused to a pathogen-inducible promoter show high resistance to $P$. infestans but high susceptibility to the necrotrophic pathogen Alternaria solani (M. Kobayashi, M. Yoshioka, S. Asai, and H. Yoshioka, unpublished data). StCDPK5VK induces production of ROS (Kobayashi et al. 2007) but not of NO. The results support the idea that ROS may play a negative role in disease resistance to $B$. cinerea or a positive role in expansion of disease lesions. Transgenic potato plants expressing a constitutively active form of MAPKK, StMEK2 $\left(S t M E K 2^{D D}\right)$ driven by the same pathogen-inducible promoter as for StCDPK5VK, are resistant to both $P$. infestans and $A$. solani (Yamamizo et al. 2006). StMEK2 ${ }^{\mathrm{DD}}$ activates SIPK and then induces both ROS and NO production (Asai et al. 2008). These results support the conclusions of this study that NO contributes to disease resistance against necrotrophic pathogens. NO may function as a key factor that adapts to a wide spectrum of pathogens.

\section{MATERIALS AND METHODS}

\section{Plant growth conditions.}

$N$. benthamiana plants were grown at $25^{\circ} \mathrm{C}$ and $70 \%$ humidity under a 16 -h photoperiod and an 8 -h-dark period in environmentally controlled growth cabinets.

\section{Fungal culture, pathogen inoculation, and assays.}

Botrytis cinerea F-016-0001, which was originally isolated from strawberry, was obtained from Nihon Nohyaku Co., Ltd (Tokyo). B. cinerea was maintained on PDA at $39 \mathrm{~g} / \mathrm{liter}$ (Difco, Detroit) at $20^{\circ} \mathrm{C}$ in the dark. The conidia were collected and were suspended in sterile potato dextrose broth at $12 \mathrm{~g} / \mathrm{liter}$ (Difco). Detached $N$. benthamiana leaves were inoculated with $5-\mu l$ droplets of conidia suspension of B. cinerea $\left(1 \times 10^{5}\right.$ or $5 \times 10^{5}$ conidia per milliliter $)$. For analyses of $\mathrm{NO}$ and ROS, 20- $\mu \mathrm{l}$ droplets of conidia suspension of $B$. cinerea $\left(5 \times 10^{5}\right.$ conidia per milliliter $)$ were used. The inoculated leaves were kept at high humidity at $23^{\circ} \mathrm{C}$ with a 16 -h photoperiod and an 8-h dark period. Lesions diameters were measured using calipers. For conductivity tests, two disks per leaf (16 $\mathrm{mm}$ diameter) were obtained from inoculated areas for each leaf and were floated in $10 \mathrm{ml}$ of distilled water for $4 \mathrm{~h}$ at room temperature with gentle shaking. Conductivity was measured with a multifunctional meter D-54 (HORIBA, Kyoto, Japan).

\section{Histochemical staining and microscopic observations.}

Trypan blue and DAB staining was done as described by Yoshioka and associates (2003). Fungal hyphal structures and dead cells were observed by staining infected leaves with trypan blue. Infected leaves were transferred to a trypan blue solution $(10 \mathrm{ml}$ of lactic acid, $10 \mathrm{ml}$ of glycerol, $10 \mathrm{~g}$ of phenol, $10 \mathrm{ml}$ of $\mathrm{H}_{2} \mathrm{O}$, and $10 \mathrm{mg}$ of trypan blue) diluted in ethanol 1:1 and were boiled for 1 to $2 \mathrm{~min}$. The leaves were then destained overnight in chloral hydrate. To visualize $\mathrm{H}_{2} \mathrm{O}_{2}$ in the infection site of $B$. cinerea, DAB staining was done. Inoculated leaves were vacuum-infiltrated with a 1 $\mathrm{mg} / \mathrm{ml}$ DAB solution ( $\mathrm{pH} 3.9$ ) and, then, were fixed on filter paper by immersion in a 3:1 solution of ethanol and acetic acid. Stained leaves were observed using a fluorescence microscope (Axio Imager, Carl Zeiss, Oberkochen, Germany) or a fluorescence stereomicroscope (MZ16FA, Leica, Wetzlar, Germany) equipped with a CCD camera (AxioCam HRc, Carl Zeiss).

\section{Detection of NO.}

NO accumulation was monitored by using NO-sensitive dye DAF-2DA (Daiichi Pure Chemicals, Tokyo) as described by Asai and associates (2008). Leaves were infiltrated with 200 $\mathrm{mM}$ sodium phosphate buffer at $\mathrm{pH} 7.4$ and $12.5 \mu \mathrm{M}$ DAF2DA, using a needleless syringe or in a vacuum using an aspirator and were incubated for $1 \mathrm{~h}$ in the dark at room temperature before observation. Fluorescence from diaminotriazolofluorescein (DAF-2T), the reaction product of DAF-2DA with NO, was captured at excitation $470 / 40 \mathrm{~nm}$ and emission $525 / 50 \mathrm{~nm}$, using a fluorescence microscope (Axio Imager, Carl Zeiss) or a fluorescence stereomicroscope (MZ16FA, Leica) equipped with a CCD camera (Color 14 bit, AxioCam HRc, Carl Zeiss). To quantify fluorescence intensity, images were obtained using the fluorescence stereomicroscope at constant acquisition time. For acquirement of low magnification images in Figure $1 \mathrm{H}$ and I, the fluorescence images were obtained at approximately threefold exposure times compared with other images used for quantification of the fluorescence intensity. The long exposure was applied to detect autofluorescence. The fluorescence intensity of the scanned entire field of the image captured by a CCD camera was quantified by determining the mean green channel values for the images with the histogram function of Adobe Photoshop 7.0 (Adobe, Seattle), as described by Boccara and associates (2005). A fluorescence image was obtained from an inoculated area per leaf and at least three inoculated areas were analyzed as replicates for each treatment. To account for background fluorescence, the corresponding mean value for noninoculated leaves infiltrated with the fluorescent dye $(19.4 \pm 1.0)$ was subtracted.

\section{Measurement of ROS.}

ROS measurements were done as described by Kobayashi and associates (2007). The relative intensity of ROS generation was determined by counting photons from L-012-mediated chemiluminescence. The $0.5 \mathrm{mM} \mathrm{L-012}$ in $10 \mathrm{mM}$ morpholinepropanesulfonic acid-KOH at $\mathrm{pH} 7.4$ was infiltrated into $N$. benthamiana leaves using a needleless syringe. Chemiluminescence was monitored continuously using a photon image processor equipped with a sensitive CCD camera (Aquacosmos 2.5, Hamamatsu Photonics, Hamamatsu City, Japan) and was quantified using the U7501 program (Hamamatsu).

\section{Immunoblotting.}

Immunoblotting was done as described by Asai and associates (2008). The protein extracts $(10 \mu \mathrm{g})$ were separated on a $12 \%$ sodium dodecyl sulfate (SDS)-polyacrylamide gel and were transferred to a nitrocellulose membrane (Schleicher \& Schuell, Keene, NH, U.S.A.). After blocking in TBS-T (50 $\mathrm{mM}$ Tris- $\mathrm{HCl}, \mathrm{pH} 7.5,150 \mathrm{mM} \mathrm{NaCl}$, and $0.05 \%$ Tween 20 ) with $5 \%$ nonfat dry milk overnight at $4{ }^{\circ} \mathrm{C}$, the membranes were incubated with SIPK-specific antiserum diluted with TBS-T at room temperature for $1 \mathrm{~h}$. After washing with TBS-T, the membranes were incubated with horseradish peroxidaseconjugated anti-rabbit immunoglobulin G antibody (Amersham, 
Tokyo) diluted with TBS-T for $1 \mathrm{~h}$ at room temperature. The antibody-antigen complex was detected by using the ECL Western-blotting detection kit (Amersham) and Light-Capture (ATTO, Tokyo).

\section{Immunocomplex kinase assay.}

The immunocomplex kinase assay was done as described by Asai and associates (2008). The protein extracts $(50 \mu \mathrm{g})$ were incubated with SIPK-specific antiserum in the immunoprecipitation buffer $(50 \mathrm{mM}$ Tris- $\mathrm{HCl}$ at $\mathrm{pH} 8.0,150 \mathrm{mM} \mathrm{NaCl}, 1 \mathrm{mM}$ ethylene diamine tetraacetate, $50 \mathrm{mM} \mathrm{NaF}, 10 \mathrm{mM} \beta$-glycerophosphate, $1 \mathrm{mM} \mathrm{Na}_{3} \mathrm{VO}_{4}$, and $1 \%$ Triton $\mathrm{X}-100$ ) at $4^{\circ} \mathrm{C}$ for 2 $\mathrm{h}$ with shaking. The mixture was then incubated in a $40-\mu \mathrm{l}$ aliquot of $50 \%$ (vol/vol) protein A-Sepharose (GE Healthcare, Little Chalfont, U.K.) at $4{ }^{\circ} \mathrm{C}$ overnight with shaking. Protein A-Sepharose complexes were pelleted by brief centrifugation, were washed three times with $1 \mathrm{ml}$ of the immunoprecipitation buffer, and then were washed three times with $1 \mathrm{ml}$ of kinase reaction buffer (20 $\mathrm{mM} N$-2-hydroxyethylpiperazine- $N^{\prime}$-2ethanesulfonic acid- $\mathrm{KOH}, \mathrm{pH} 7.6,10 \mathrm{mM} \mathrm{MgCl}$ and $1 \mathrm{mM}$ dithiothreitol). The kinase activity in the complex was assayed at $25^{\circ} \mathrm{C}$ for $30 \mathrm{~min}$ in a final volume of $15 \mu$ containing 0.4 $\mathrm{mg}$ of myelin basic protein (MBP) per milliliter, $100 \mu \mathrm{M}$ ATP, and $8 \mathrm{nCi}$ of $\left[\gamma^{32} \mathrm{P}\right]$ ATP per milliliter. The reaction was stopped by adding SDS-polyacrylamide gel electrophoresis sample loading buffer. After electrophoresis on 15\% SDSpolyacrylamide gel, the phosphorylated MBP was visualized by autoradiography.

\section{RT-PCR.}

Total RNA from $N$. benthamiana leaves was prepared by using TRIzol reagent according to the procedure of the manufacturer (Invitrogen, Carlsbad, CA, U.S.A.). RT-PCR was carried out using a commercial kit (ReverTra Ace - $\alpha$-, TOYOBO, Osaka, Japan). PCR was done with ExTaq (Takara, Tokyo) at denaturing, annealing, and extension temperatures $94^{\circ} \mathrm{C}$ for 30 $\mathrm{s}, 56^{\circ} \mathrm{C}$ for $30 \mathrm{~s}$, and $72^{\circ} \mathrm{C}$ for $40 \mathrm{~s}$, respectively, for 24 to 26 cycles. Gene-specific primers of each sequence were: NbRBOHB (5'-TTTTCTCTGAGGTTTGCCAGCCACCA-3', 5'-GCCTTCATGTTGTTGACAATGTCTTT-3'), NbNOAl (5'-ATGGCGCCTAAACTCCTTGCTC-3', 5'-TTCA TTGTGGCCTCCACAACCC-3'),

NbPR-1 (5'-CATAACACAGCTCGTGCAGATGTAG-3', 5'-A ACCACCTGAGTATAGTGTCCACAC-3'), NbLOX (5'-CCTTAAGAGGAGATGGAACT-3', 5'-TCTAAG CTCATAAGCAATGG-3'),

NbERF1 (5'-GGCGAATTTTCCGGGAGACT-3', 5'-GGCTCC GATTTTACTTCGCC-3'),

NbGST (5'-GTGTTAGTGGCAGCTCTTATAGTCG-3', 5'-GC TTTCCATTGTGAATTAGCACTGG-3'), and NbCAT1 (5'-AACAGTACCCAATTCCTTTTCGTGT-3', 5'-G TTTAATACTCCAAACTGCAACTTC- $3^{\prime}$ ).

As a control for equal cDNA amounts in each reaction, PCR was done with primers for $N b E F-1 \alpha$ for 26 cycles (5'-CCTCA AGAAGGTTGGATACAAC-3', 5'-TCTTGGGCTCATTAATC TGGTC-3'). The PCR products were separated on $1.0 \%$ agarose gel, were stained with ethidium bromide for visualization.

\section{VIGS.}

VIGS was done as described by Ratcliff and associates (2001). The following primers were used to amplify cDNA fragments from $N$. benthamiana, using the $N$. benthamiana cDNA library as a template (Yoshioka et al. 2003). Restriction sites were added to the 5' end of the forward and reverse primer for cloning into TRV vector pTV00 (RNA2): NbNOA1-F-BamHI (5'-CGGGATCCCGGAGTCACAGATAG CTGACCG-3') and NbNOA1-R-ClaI (5'-CCATCGATGGCT
GTCCTCCAGCTTTGC-3') (restriction sites are underlined), which produced a 478-bp fragment, and NbRBOHB-F-ClaI (5'-CCATCGATGTTAAACAAACGAGGCGGCA-3') and NbRBOHB-R-HindIII (5'-CCCAAGCTTTACATTCTCCAAA TTTGGCAC-3'), which produced a 500-bp fragment. $N$. benthamiana was infected with viruses by Agrobacterium-mediated transient expression of infectious constructs. pBINTRA6 (RNA1) and pTV00 containing the inserts (RNA2) were transformed by electroporation separately into A. tumefaciens GV3101, which includes the transformation helper plasmid pSoup (Hellens et al. 2000). A mixture of equal parts of Agrobacterium suspensions of RNA1 and RNA2 was inoculated into 2- to 3-week-old $N$. benthamiana seedlings. The inoculated plants were grown under a 16-h light and an 8-h dark cycle at $23^{\circ} \mathrm{C}$. The upper leaves of the inoculated plants were used for assays 3 to 4 weeks after inoculation.

\section{ACKNOWLEDGMENTS}

We thank P. Mullineaux and R. Hellens for providing the pGreen binary vector, D. C. Baulcombe for providing the pTV00 vector, Nihon Nohyaku Co., Ltd for providing Botrytis cinerea, and Leaf Tobacco Research Center, Japan Tobacco Inc., for providing $N$. benthamiana seeds. We also thank the members of the Radioisotope Research Center, Nagoya University for technical assistance. This work was supported by the Program for Promotion of Basic Research Activities for Innovative Biosciences (PROBRAIN) and by a grant-in-aid for Scientific Research (A) from the Ministry of Education, Science and Culture of Japan.

\section{LITERATURE CITED}

Asai, S., Ohta, K., and Yoshioka, H. 2008. MAPK signaling regulates nitric oxide and NADPH oxidase-dependent oxidative bursts in Nicotiana benthamiana. Plant Cell 20:1390-1406.

Asselbergh, B., Curvers, K., Franca, S. C., Audenaert, K., Vuylsteke, M., van Breusegem, F., and Hofte, M. 2007. Resistance to Botrytis cinerea in sitiens, an abscisic acid-deficient tomato mutant, involves timely production of hydrogen peroxide and cell wall modifications in the epidermis. Plant Physiol. 144:1863-1877.

Besson-Bard, A., Pugin, A., and Wendehenne, D. 2008. New insights into nitric oxide signaling in plants. Annu. Rev. Plant Biol. 59:21-39.

Boccara, M., Mills, C. E., Zeier, J., Anzi, C., Lamb, C., Poole, R. K., and Delledonne, M. 2005. Flavohaemoglobin HmpX from Erwinia chrysanthemi confers nitrosative stress tolerance and affects the plant hypersensitive reaction by intercepting nitric oxide produced by the host. Plant J. 43:226-237.

Butt, Y. K.-C., Lum, J. H.-K., and Lo, S. C.-L. 2003. Proteomic identification of plant proteins probed by mammalian nitric oxide synthase antibodies. Planta 216:762-771.

Clarke, A., Desikan, R., Hurst, R. D., Hancock, J. T., and Neill, S. J. 2000. NO way back: Nitric oxide and programmed cell death in Arabidopsis thaliana suspension cultures. Plant J. 24:667-677.

Crawford, N. M., Galli, M., Tischner, R., Heimer, Y. M., Okamoto, M., and Mack, A. 2006. Response to Zemojtel et al: Plant nitric oxide synthase: Back to square one. Trends Plant Sci. 11:526-527.

Delledonne, M., Xia, Y., Dixon, R. A., and Lamb, C. 1998. Nitric oxide functions as a signal in plant disease resistance. Nature 394:585-588.

Delledonne, M., Zeier, J., Marocco, A., and Lamb, C. 2001. Signal interactions between nitric oxide and reactive oxygen intermediates in the plant hypersensitive disease resistance response. Proc. Natl. Acad. Sci. U.S.A. 98:13454-13459.

Dickman, M. B., Park, Y. K., Oltersdorf, T., Li, W., Clemente, T., and French, R. 2001. Abrogation of disease development in plants expressing animal antiapoptotic genes. Proc. Natl. Acad. Sci. U.S.A. 98:6957-6962.

Elad, Y. 1992. The use of antioxidants (free radical scavangers) to control grey mould (Botrytis cinerea) and white mould (Sclerotinia sclerotionumm) in various crops. Plant Pathol. 41:417-426.

Ferrari, S., Plotnikova, J. M., de Lorenzo, G., and Ausubel, F. M. 2003. Arabidopsis local resistance to Botrytis cinerea involves salicylic acid and camalexin and requires EDS4 and PAD2, but not SID2, EDS5 or PAD4. Plant J. 35:193-205.

Flores-Perez, U., Sauret-Gueto, S., Gas, E., Jarvis, P., and RodriguezConcepcion, M. 2008. A mutant impaired in the production of plastome-encoded proteins uncovers a mechanism for the homeostasis of 
isoprenoid biosynthetic enzymes in Arabidopsis plastids. Plant Cell 20:1303-1315.

Floryszak-Wieczorek, J., Arasimowicz, M., Milczarek, G., Jelen, H., and Jackowiak, H. 2007. Only an early nitric oxide burst and the following wave of secondary nitric oxide generation enhanced effective defence responses of pelargonium to a necrotrophic pathogen. New Phytol. 175:718-730

Garcia-Mata, C., and Lamattina, L. 2003. Abscisic acid, nitric oxide and stomatal closure-Is nitrate reductase one of the missing links. Trends Plant Sci. 8:20-26.

Govrin, E., and Levine, A. 2000. The hypersensitive response facilitates plant infection by the necrotrophic pathogen Botrytis cinerea. Curr. Biol. 10:751-757.

Guo, F.-Q., Okamoto, M., and Crawford, N. M. 2003. Identification of a plant nitric oxide synthase gene involved in hormonal signaling. Science 302:100-103.

He, Y., Tang, R.-H., Hao, Y., Stevens, R. D., Cook, C. W., Ahn, S. M., Jing, L., Yang, Z., Chen, L., Guo, F., Fiorani, F., Jackson, R. B., Crawford, N. M., and Pei, Z.-M. 2004. Nitric oxide represses the Arabidopsis floral transition. Science 305:1968-1971.

Hellens, R. P., Edwards, E. A., Leyland, N. R., Bean, S., and Mullineaux, P. M. 2000. pGreen: A versatile and flexible binary Ti vector for Agrobacterium-mediated plant transformation. Plant Mol. Biol. 42:819-832.

Hong, J. K., Yun, B.-W., Kang, J.-G., Raja, M. U., Kwon, E., Sorhagen, K., Chu, C., Wang, Y., and Loake, G. J. 2008. Nitric oxide function and signalling in plant disease resistance. J. Exp. Bot. 59:147-154.

Jones, J. D. G., and Dangl, J. L. 2006. The plant immune system. Nature 444:323-329.

Kars, I., Krooshof, G. H., Wagemakers, L., Joosten, R., Benen, J. A., and van Kan, J. A. 2005. Necrotizing activity of five Botrytis cinerea endopolygalacturonases produced in Pichia pastoris. Plant J. 43:213225

Kato, H., Asai, S., Yamamoto-Katou, A., Yoshioka, H., Doke, N., and Kawakita, K. 2008. Involvement of $N b N O A 1$ in NO production and defense responses in INF1-treated Nicotiana benthamiana. J. Gen. Plant Pathol. 74:15-23.

Klessig, D. F., Durner, J., Noad, R., Navarre, D. A., Wendehenne, D., Kumar, D., Zhou, J. M., Shah, J., Zhang, S., Kachroo, P., Trifa, Y., Pontier, D., Lam, E., and Silva, H. 2000. Nitric oxide and salicylic acid signalling in plant defense. Proc. Natl. Acad. Sci. U.S.A. 97:884955.

Kobayashi, M., Kawakita, K., Maeshima, M., Doke, N., and Yoshioka, H. 2006. Subcellular localization of Strboh proteins and NADPH-dependent $\mathrm{O}_{2}{ }^{-}$-generating activity in potato tuber tissues. J. Exp. Bot. 57:13731379 .

Kobayashi, M., Ohura, I., Kawakita, K., Yokota, N., Fujiwara, M., Shimamoto, K., Doke, N., and Yoshioka, H. 2007. Calcium-dependent protein kinases regulate the production of reactive oxygen species by potato NADPH oxidase. Plant Cell 19:1065-1080.

Kunz, C., Vandelle, E., Rolland, S., Poinssot, B., Bruel, C., Cimerman, A., Zotti, C., Moreau, E., Vedel, R., Pugin, A., and Boccara, M. 2006. Characterization of a new, nonpathogenic mutant of Botrytis cinerea with impaired plant colonization capacity. New Phytol. 170:537-550

Ma, W., Smigel, A., Tsai, Y.-C., Braam, J., and Berkowitz, G. A. 2008. Innate immunity signaling: Cytosolic $\mathrm{Ca}^{2+}$ elevation is linked to downstream nitric oxide generation through the action of calmodulin or a calmodulin-like protein. Plant Physiol. 148:818-828.

Moreau, M., Lee, G. I., Wang, Y., Crane, B. R., and Klessig, D. F. 2008. AtNOS/A1 is a functional Arabidopsis thaliana cGTPase and not a nitric oxide synthase. J. Biol. Chem. 283:32957-32967.

Muckenschnabel, I., Goodman, B. A., Deighton, N., Lyon, G. D., and Williamson, B. 2001. Botrytis cinerea induces the formation of free radicals in fruits of Capsicum annuum at positions remote from the site of infection. Protoplasma 218:112-116.

Muckenschnabel, I., Goodman, B. A., Williamson, B., Lyon, G. D., and Deighton, N. 2002. Infection of leaves of Arabidopsis thaliana by Botrytis cinerea: Changes in ascorbic acid, free radicals and lipid peroxidation products. J. Exp. Bot. 53:207-214.

Muckenschnabel, I., Gronover, C. S., Deighton, N., Goodman, B. A. Lyon, G. D., Stewart, D., and Williamson, B. 2003. Oxidative effects in uninfected tissue in leaves of French bean (Phaseolus vulgaris) containing soft rots caused by Botrytis cinerea. J. Sci. Food Agric. 83:507514

Poinssot, B., Vandelle, E., Bentejac, M., Adrian, M., Levis, C., Brygoo, Y., Garin, J., Sicilia, F., Coutos-Thevenot, P., and Pugin, A. 2003. The endopolygalacturonase 1 from Botrytis cinerea activates grapevine defense reactions unrelated to its enzymatic activity. Mol. Plant-Microbe Interact. 16:553-564
Prats, E., Carver, T. L. W., and Mur, L. A. J. 2008. Pathogen-derived nitric oxide influences formation of the appressorium infection structure in the phytopathogenic fungus Blumeria graminis. Res. Microbiol. 159:476-480

Ratcliff, F., Martin-Hernandez, A. M., and Baulcombe, D. C. 2001. Tobacco rattle virus as a vector for analysis of gene function by silencing. Plant J. 25:237-245.

Ren, D., Liu, Y., Yang, K.-Y., Han, L., Mao, G., Glazebrook, J., and Zhang, S. 2008. A fungal-responsive MAPK cascade regulates phytoalexin biosynthesis in Arabidopsis. Proc. Natl. Acad. Sci. U.S.A 105:5638-5643.

Segmuller, N., Kokkelink, L., Giesbert, S., Odinius, D., van Kan, J., and Tudzynski, P. 2008. NADPH oxidases are involved in differentiation and pathogenicity in Botrytis cinerea. Mol. Plant-Microbe Interact. 21:808-819.

Shi, S., Wang, G., Wang, Y., Zhang, L., and Zhang, L. X. 2005. Protective effect of nitric oxide against oxidative stress under ultraviolet-B radiation. Nitric Oxide 13:1-9.

Simon-Plas, F., Elmayan, T., and Blein, J.-P. 2002. The plasma membrane oxidase NtrbohD is responsible for AOS production in elicited tobacco cells. Plant J. 31:137-147.

Sudhamsu, J., Lee, G. I., Klessig, D. F., and Crane, B. R. 2008. The structure of YqeH: An AtNOS1/AtNOA1 ortholog that couples GTP hydrolysis to molecular recognition. J. Biol. Chem. 283:32968-32978.

Tada, Y., Spoel, S. H., Pajerowska-Mukhtar, K., Mou, Z., Song, J., Wang, C., Zuo, J., and Dong, X. 2008. Plant immunity requires conformational charges of NPR1 via S-nitrosylation and thioredoxins. Science 321:952-956.

ten Have, A., Mulder, W., Visser, J., and van Kan, J. A. 1998. The endopolygalacturonase gene Bcpgl is required for full virulence of Botrytis cinerea. Mol. Plant-Microbe Interact. 11:1009-1016.

Tiedemann, A. V. 1997. Evidence for a primary role of active oxygen species in induction of host cell death during infection of bean leaves with Botrytis cinerea. Physiol. Mol. Plant Pathol. 50:151-166.

Torres, M. A., and Dangl, J. L. 2005. Functions of the respiratory burst oxidase in biotic interactions, abiotic stress and development. Curr. Opin. Plant Biol. 8:397-403.

Torres, M. A., Dangl, J. L., and Jones, J. D. G. 2002. Arabidopsis gp91 ${ }^{\text {phox }}$ homologues AtrbohD and AtrbohF are required for accumulation of reactive oxygen intermediates in the plant defense response. Proc. Natl. Acad. Sci. U.S.A. 99:517-522.

Torres, M. A., Jones J. D. G., and Dangl, J. L. 2006. Reactive oxygen species signaling in response to pathogens. Plant Physiol. 141:373-378

Unger, C., Kleta, S., Jandl, G., and Tiedemann, A. V. 2005. Suppression of the defence-related oxidative burst in bean leaf tissue and bean suspension cells by the necrotrophic pathogen Botrytis cinerea. J. Phytopathol. 153:15-26.

van Baarlen, P., Staats, M., and van Kan, J. A. L. 2004. Induction of programmed cell death in lily by the fungal pathogen Botrytis elliptica. Mol. Plant Pathol. 5:559-574.

van Baarlen, P., Woltering, E. J., Staats, M., and van Kan, J. A. L. 2007. Histochemical and genetic analysis of host and non-host interactions of Arabidopsis with three Botrytis species: An important role for cell death control. Mol. Plant Pathol. 8:41-54.

Vandelle, E., Poinssot, B., Wendehenne, D., Bentéjac, M., and Alain, P. 2006. Integrated signaling network involving calcium, nitric oxide, and active oxygen species but not mitogen-activated protein kinases in BcPG1-elicited grapevine defenses. Mol. Plant-Microbe Interact. 19:429-440.

Vandenabeele, S., van der Kelen, K., Dat, J., Gadjev, I., Boonefaes, T., Morsa, S., Rottiers, P., Slooten, L., van Montagu, M., Zabeau, M., Inze D., and van Breusegem, F. 2003. A comprehensive analysis of hydrogen peroxide-induced gene expression in tobacco. Proc. Natl. Acad. Sci. U.S.A. 100:16113-16118.

van Kan, J. A. L. 2006. Licensed to kill: The lifestyle of a necrotrophic plant pathogen. Trends Plant Sci. 11:247-253.

Wang, J., and Higgins, V. J. 2005. Nitric oxide has a regulatory effect in the germination of conidia of Colletotrichum coccodes. Fungal Genet. Biol. 42:284-292.

Wendehenne, D., Durner, J., and Klessig, D. F. 2004. Nitric oxide: A new player in plant signalling and defence responses. Curr. Opin. Plant Biol. 7:449-455.

Xing, Y., Jia, W., and Zhang, J. 2008. AtMKK1 mediates ABA-induced CAT1 expression and $\mathrm{H}_{2} \mathrm{O}_{2}$ production via AtMPK6-coupled signaling in Arabidopsis. Plant J. 54:440-451.

Yamamizo, C., Kuchimura, K., Kobayashi, A., Katou, S., Kawakita, K., Jones, J. D. G., Doke, N., and Yoshioka, H. 2006. Rewiring mitogenactivated protein kinase cascade by positive feedback confers potato blight resistance. Plant Physiol. 140:681-692.

Yoshioka, H., Numata, N., Nakajima, K., Katou, S., Kawakita, K. 
Rowland, O., Jones, J. D. G., and Doke, N. 2003. Nicotiana benthamiana gp91 $1^{\text {phox }}$ homologs NbrbohA and NbrbohB participate in $\mathrm{H}_{2} \mathrm{O}_{2}$ accumulation and resistance to Phytophthora infestans. Plant Cell 15:706-718.

Yoshioka, H., Sugie, K., Park, H.-J., Maeda, H., Tsuda, N., Kawakita, K., and Doke, N. 2001. Induction of plant gp91 phox homolog by fungal cell wall, arachidonic acid, and salicylic acid in potato. Mol. Plant-Microbe Interact. 14:725-736.

Zago, E., Morsa, S., Dat, J. F., Alard, P., Ferrarini, A., Inze, D., Delledonne, M., and van Breusegem, F. 2006. Nitric oxide- and hydrogen peroxideresponsive gene regulation during cell death induction in tobacco. Plant Physiol. 141:404-411.
Zeidler, D., Zahringer, U., Gerber, I., Dubery, I., Hartung, T., Bors, W., Hutzler, P., and Durner, J. 2004. Innate immunity in Arabidopsis thaliana: Lipopolysaccharides activate nitric oxide synthase (NOS) and induce defense genes. Proc. Natl. Acad. Sci. U.S.A. 101:1581115816.

Zemojtel, T., Frohlich, A., Palmieri, M. C., Kolanczyk, M., Mikula, I., Wyrwicz, L. S., Wanker, E. E., Mundlos, S., Vingron, M., Martasek, P., and Durner, J. 2006. Plant nitric oxide synthase: A never-ending story? Trends Plant Sci. 11:524-525.

Zhao, M.-G., Tian, Q.-Y., and Zhang, W.-H. 2007. Nitric oxide synthasedependent nitric oxide production is associated with salt tolerance in Arabidopsis. Plant Physiol. 144:206-217. 